\title{
SEX DETERMINATION OF FEMUR: A MORPHOMETRIC ANALYSIS IN THE NORTH INDIAN POPULATION
}

\author{
Aprajita Sikka1, Anjali Jain ${ }^{2}$ \\ ${ }^{1}$ Associate Professor, Department of Anatomy, Christian Medical College, Ludhiana. \\ 2Professor and Head, Department of Anatomy, Christian Medical College, Ludhiana.
}

\begin{abstract}
Bones are an important tool for establishing the biological profile of an individual. In the absence of skull and pelvis, long bones can play a major role in determining the sex. Femur is the longest and strongest bone of the body and resists environmental effects and hence becomes important in medico-legal investigations.
\end{abstract}

\section{AIMS}

To determine the sex of 180 femora and to set up baseline parameters for the North Indian population with the help of demarcating and limiting values.

\section{MATERIALS AND METHODS}

Seven parameters were studied in 180 femora to determine their sex. Mean and standard deviation were calculated. They were analysed using student ' $\mathrm{t}$ ' test, Hotelling $\mathrm{T}^{2}$ square test for multivariate analysis and discriminant function analysis. Also, demarcating and limiting values were calculated for each parameter.

\section{RESULTS}

The difference between males and females for all parameters was highly significant. Males showed higher values as compared to females. By multivariate analysis also, $\mathrm{p}$ value was less than 0.001 . We could correctly classify $90 \%$ bones using discriminant function analysis.

\section{CONCLUSION}

Femur exhibits significant sexual dimorphism. Different populations require their own standards of sex determination. The accuracy of classification increases with increase in number of parameters.

\section{KEYWORDS}

Femur, Anthropometry, Forensic Medicine, Sex Determination, Discriminant Function Analysis.

HOW TO CITE THIS ARTICLE: Sikka A, Jain A. Sex determination of femur: a morphometric analysis in the North Indian population. J. Evolution Med. Dent. Sci. 2016;5(59):4056-4059, DOI: 10.14260/jemds/2016/929

\section{INTRODUCTION}

The femur is the longest and strongest bone of the body. Its length is associated with striding gait, its strength with weight and muscular forces.[1] It is widely studied to determine the stature and locomotion pattern, for sex identification in skeletal remains as it shows significant variation between individuals. ${ }^{[2]}$ Owing to its robustness and strength, it is most likely to resist environmental effects and animal activities. ${ }^{[3]}$

Bones are an important tool in establishing the biological profile of an individual. The first step in creating a profile and establishing the identity of an individual is determination of sex, as subsequent methods of age and stature determination are highly sex dependent.[3] Skull and pelvis are considered to be the most sexually dimorphic, but in their absence sex has to be determined from available bones. ${ }^{[4]}$ Long bones are frequently recovered intact. Of these, femur is considered most sexually dimorphic. The reasons for this can be manifold;

Financial or Other, Competing Interest: None.

Submission 16-06-2016, Peer Review 10-07-2016,

Acceptance 16-07-2016, Published 22-07-2016.

Corresponding Author:

Dr. Aprajita Sikka,

Associate Professor,

Department of Anatomy,

Christian Medical College,

Brown Road, Ludhiana-141008.

E-mail: aprajitasatija@gmail.com

DOI: $10.14260 /$ jemds/2016/929 namely, the differences in morphology of pelvis due to greater pelvic breadth in females influenced by the reproductive function.[1], genetic differences that influence body size and proportions and lastly differences in musculature.[5,6] Female femora are usually shorter and exhibit greater obliquity. It is seen that the typical male bones are 'large, long, rough and massive' than the typical female long bones. The study on sexual dimorphism is based on the principle that the axial skeleton weight of the male is relatively and absolutely heavier than that of the female and the initial impact of this weight is borne by the femur in transmission of the body weight. [1,7] Hence, in the present times of increasing violence, accidents and mass disasters when encountering human skeletal remains has become common; femur can play an important role in determining sex.

The process of sex determination in unknown skeletal materials has to be accurate. It usually depends on the available fragmented or isolated remains; ageing and nonavailability of standards.[4] Though there have been previous studies on sexual dimorphism in femur, it has been found that magnitude of sex related differences depends on the particular regional population. It is dependent on race, dietary habits, lifestyle, cultural practices, etc.[6,8] India is a land of diversity with different geographical and climatic zones. Hence, there is wide variation in anthropometric dimensions between different populations. Therefore, each population needs its own set of baseline parameters and anthropometric determinants. The present study was therefore planned to 
determine the sex of femur and also to establish demarcating and limiting values for femora belonging to North India, especially Punjab. Another objective was to conduct a discriminant function analysis of sexual dimorphism based on femur and set up standards for North Indian population.

\section{MATERIALS AND METHODS}

The present study was conducted on 180 femora of unknown sex over a period of one year. The bones were already present in the Department and had been collected from dissected cadavers. All intact, well-formed and adult femora were included in the study. Pathological, deformed, damaged or broken bones were excluded from the study.

A total of seven parameters were studied. Measurements were taken using an osteometric board and vernier callipers.

\section{Following Parameters were Measured for each Bone.[3]}

- Maximum Length of Femur (MLF): The straight distance between the highest point on the head and the lowest point on the medial condyle.

- Maximum Mid Shaft Antero Posterior Diameter: The antero-posterior distance measured at the midpoint of the maximum length.

- Proximal Breadth (PB): The distance between the most medial point on the head to the most lateral point on the greater trochanter.

- Vertical Diameter of Neck: The minimum diameter of femoral neck in a plane perpendicular to the head-neck midline.

- Vertical Diameter of Head (VDH): The straight distance between the highest and the lowest point on the head.

- Transverse Diameter of Head (TDH): The straight distance between the most laterally projected points on the head perpendicular to the VDH.

- Epicondylar Breadth (ECB): The maximum distance between the two most projecting points on the lateral and medial epicondyles.

The measurements were recorded, tabulated and analysed statistically. Mean and Standard Deviation (S.D.) for each parameter were worked out.

To assess the efficacy of statistical tests in determining sex and to predict the proportion of individuals which can be identified correctly either male or female, a limiting value was worked out, either side of which represented a particular sex. To determine this, demarcating and limiting values were calculated assuming normal distribution. Calculated range is mean \pm 3 S.D., covering $99 \%$ population. For instance, in males mean-3 S.D. be denoted as ' $a$ ', mean+3 S.D. denoted as ' $b$ '; then $a$ to $b$ is calculated range for males. Similarly, mean-3 S.D. be denoted by ' $x$ ' and mean+3 S.D. be denoted as ' $y$ '; then $x$ to $y$ is calculated range for females. The demarcating point for females is ' $a$ ' below which all will be females and ' $y$ ' is demarcating point for males above which all will be males. Based on the above values, limiting value was worked out. A limiting value is the value above which majority bones were male and below which most bones were female.

Statistical tests used were student's ' $t$ ' test, Hotelling $T^{2}$ test for multivariate analysis and discriminant function analysis with SPSS. Discriminant function analysis is used to develop an index to have maximum discrimination among two groups where variation is maximum among groups and minimum within groups. We developed a discriminant function on 120 bones $(2 / 3$ of the total 180$)$ taken randomly and then based on this, predicted the sex of the rest of 60 (Which were not a part of the model) bones to test the efficacy and validity of the function developed.

\section{RESULTS}

The current study was conducted to determine the sex of 180 femora. The metric parameters are summarised in Table 1.

As is evident from Table 1, there were 115 male bones and 65 female bones. The mean values for all parameters are greater in males as compared to females. Using student's ' $\mathrm{t}$ ' test, $p<0.001$ for all parameters showing that the difference is highly significant for all parameters. The standard deviation is also higher in males for all the above parameters denoting that males show greater variability as compared to females.

The demarcating and limiting values are summarised in Table 2. It is an extension of sex determining values for metric traits. Limiting value of maximum length of femur could correctly classify $80.6 \%$ males and $87.8 \%$ females. With proximal breadth, $94.3 \%$ males and $70 \%$ females could be correctly categorised. Considering the vertical diameter of head, $94 \%$ males as well as females could be correctly classified; $83.5 \%$ males and $93 \%$ could be categorised using the limiting value of transverse diameter of head. Using the mid shaft diameter and vertical diameter of neck, $95 \%$ females could be correctly categorised, though only $70 \%$ males could be identified; $94 \%$ males and $86.2 \%$ males were correctly identified using epicondylar breadth. It is clear from above that more females could be correctly identified with the use of limiting values.

As the probability value for different parameters varies indicating different level of significance, Hotelling T2 test was applied to understand how these parameters behave collectively in determining sex. The calculated variance at $\mathrm{F}_{7} 172$ by Hotelling $\mathrm{T}^{2}$ test for multivariate analysis is 40.90 , which is highly significant with a $p$ value of $<0.001$. This demonstrates that all parameters when taken together exhibit effective sexual dimorphism.

For the model $\left(\mathrm{n}_{1}=120\right)$ bones using discriminant function analysis, 108 bones could be correctly classified, i.e. a correct classification of $90 \%$. When this model was tested on the rest of the 60 bones, 57 bones could be correctly classified, i.e. with an accuracy of $94 \%$.

On using different combinations of various parameters, we found that maximum accuracy was achieved with epicondylar breadth and vertical diameter of head taken together. Using the two together, an accuracy of $84 \%$ was achieved. On considering all seven parameters together, this increased to $90 \%$, hence more the number of parameters we consider more will be the probability of correct classification.

\begin{tabular}{|c|c|c|c|c|c|}
\hline \multirow{2}{*}{ Parameter } & \multicolumn{2}{|c|}{$\begin{array}{c}\text { Male } \\
\text { (n=115) }\end{array}$} & \multicolumn{2}{c|}{$\begin{array}{c}\text { Female } \\
\text { (n=65) }\end{array}$} & \multirow{2}{*}{$\mathbf{p}$} \\
\cline { 2 - 5 } & $\begin{array}{c}\text { Mean } \\
\text { (cm) }\end{array}$ & S.D. & $\begin{array}{c}\text { Mean } \\
\text { (cm) }\end{array}$ & S.D. & \\
\hline Maximal Length & 47.04 & 2.38 & 42.72 & 3.13 & $<0.001$ \\
\hline Proximal Breadth & 9.08 & 0.54 & 8.07 & 0.51 & $<0.001$ \\
\hline $\begin{array}{c}\text { Vertical Diameter } \\
\text { of Head }\end{array}$ & 4.38 & 0.26 & 3.83 & 0.28 & $<0.001$ \\
\hline $\begin{array}{c}\text { Transverse } \\
\text { Diameter of Head }\end{array}$ & 4.40 & 0.25 & 3.84 & 0.29 & $<0.001$ \\
\hline
\end{tabular}




\begin{tabular}{|c|c|c|c|c|c|}
\hline $\begin{array}{c}\text { Epicondylar } \\
\text { Breadth }\end{array}$ & 7.76 & 0.46 & 6.89 & 0.40 & $<0.001$ \\
\hline $\begin{array}{c}\text { Vertical Diameter } \\
\text { of Neck }\end{array}$ & 3.13 & 0.21 & 2.64 & 0.28 & $<0.001$ \\
\hline Mid Shaft Diameter & 2.85 & 0.25 & 2.44 & 0.25 & $<0.001$ \\
\hline
\end{tabular}

Table 1: Descriptive Analysis of Metric Parameters in Males and Females

\begin{tabular}{|c|c|c|c|}
\hline \multirow{2}{*}{ Parameter } & $\begin{array}{c}\text { Males } \\
(n=115)\end{array}$ & $\begin{array}{c}\text { Females } \\
(n=65)\end{array}$ & \multirow{2}{*}{$\begin{array}{c}\text { Limiting } \\
\text { Value } \\
\text { (cm) }\end{array}$} \\
\hline & $\begin{array}{l}\text { Demarcating } \\
\text { Point 'y' }(\mathrm{cm})\end{array}$ & $\begin{array}{l}\text { Demarcating } \\
\text { Point 'a' (cm) }\end{array}$ & \\
\hline $\begin{array}{l}\text { Maximal } \\
\text { Length }\end{array}$ & 52.1 & 39.9 & 46.0 \\
\hline $\begin{array}{l}\text { Proximal } \\
\text { Breadth }\end{array}$ & 8.6 & 7.5 & 8.0 \\
\hline $\begin{array}{c}\text { Vertical } \\
\text { Diameter of } \\
\text { Head } \\
\end{array}$ & 4.7 & 3.6 & 4.1 \\
\hline $\begin{array}{c}\text { Transverse } \\
\text { Diameter of } \\
\text { Head } \\
\end{array}$ & 4.7 & 3.7 & 4.2 \\
\hline \begin{tabular}{|c|} 
Epicondylar \\
Breadth \\
\end{tabular} & 8.1 & 6.4 & 7.2 \\
\hline \begin{tabular}{|c|} 
Vertical \\
Diameter of \\
Neck
\end{tabular} & 4.5 & 2.5 & 3.5 \\
\hline $\begin{array}{l}\text { Mid Shaft } \\
\text { Diameter }\end{array}$ & 3.7 & 2.1 & 2.9 \\
\hline
\end{tabular}

\section{DISCUSSION}

The present study was conducted using multiple parameters to ascertain the sex of femur in the North Indian population. Though, there have been previous studies by several workers in different populations; according to Krogman and Iscan, standards of morphological and morphometric attributes in the skeleton may differ with the population samples involved and this is true with reference to dimensions and indices (Average and range) and as a general rule, standards should be used with reference to the group from which they are drawn and upon which they are based.[9,10] Kate working on different femora from different regions of India found that the values showed a regional variation and also a downward gradient from North to South.[11,12]

Reliability of sexual dimorphism depends on magnitude of sexual dimorphism exhibited in a population, availability of skeletal elements, anatomical areas of the bone preserved and degree of preservation. The variables most suited for identifying sex vary in different populations demonstrating the population specific nature of sexual dimorphism. Hence, the need for establishing baseline parameters for the North Indian population, especially Punjab through the current study.

These parameters are not only useful in medico-legal practice, but are of use to anatomists, orthopaedicians also.

Length of femur is an important and reliable skeletal element for sex determination.[13] Mean maximum length was $47.04 \mathrm{~cm}$ in males and 42.72 in females. It was higher in males as compared to females, which is similar to previous works.[3,7,10,13-15] The mean values were lower in studies on Japanese and Thai populations.[16,17], which supports the inference that these parameters differ with the population under consideration. This difference in mean length may possibly be a result of factors affecting bone morphology like genetic constitution, diet, nutrition status, environment and physical activity.[10]

The mean proximal breadth was $9.08 \mathrm{~cm}$ and $8.07 \mathrm{~cm}$ in males and females respectively. The difference between the two is highly significant. In a study on South Indian population, the mean values were lower and the $\mathrm{p}<0.04$ which is less than the present study $(\mathrm{p}<0.001) .{ }^{[2]}$

The mean for vertical diameter of head and transverse diameter of head was $4.38 \mathrm{~cm}$ and $4.40 \mathrm{~cm}$ respectively in males and $3.83 \mathrm{~cm}$ and $3.84 \mathrm{~cm}$ respectively in females. The values are higher when compared to a study on the South Indian population, but are similar to studies on North Indian population. $[2,3,15,18]$ Wu concluded that the maximum diameter of head is the best single variable for determination of sex.[19] The knowledge of various dimensions of head in both sexes will not only help the anatomists and forensic experts in sexing the femora, but will also be of immense importance in prosthesis of femoral head which may be used by the orthopaedic surgeons in femoral head replacement surgery. ${ }^{[12]}$

The mean epicondylar breadth was higher in males as compared to females $(7.76 \mathrm{~cm}$ and $6.89 \mathrm{~cm}$ respectively). This is in agreement with previous studies.[2,3,7,16] Mid shaft diameter is also higher in males, which is similar to previous workers.[3,15]

Some of the powerful methods of sex determination from skeletal element are based upon the application of statistical analysis to osteological material. Discriminant function analysis is one of the sophisticated mathematical approaches.[17] The most common application of discriminant function analysis is to include many measures in the study, in order to determine the ones that discriminate between groups. The prediction accuracies vary from $70.5 \%$ to $83.6 \%$ in the North Indian population. ${ }^{[3]}$ This is higher in our study with a value of $90 \%$.

The present study also uses multivariate analysis, which shows that all parameters taken together also show significant dimorphism.

The discriminant function analysis using the combination of vertical diameter of head and epicondylar breadth shows a classification accuracy of $84 \%$. This is lower than the result (92.1\%) observed by Purkait and Chandra.[7] The classification accuracy increased to $90 \%$ when all seven parameters were considered together. This is similar to previous studies where prediction accuracy increases with increase in number of parameters. ${ }^{[7]}$

Previous researchers have concluded that sexual dimorphism is exhibited more in width measurements than length. This may be due to the differential cortical remodelling that has its maximum impact on breadth. While length of a bone stops to grow at an earlier age due to epiphyseal fusion, width wise growth continues potentially unlimited. The cortical remodelling that continues throughout the life of an individual bearing the effect of physical activities related to occupation, nutrition, etc. may result in subsequent dimorphism.[3]

\section{CONCLUSION}

The results of the present study clearly reaffirm the marked sexual dimorphism exhibited by femur. The current study clearly demonstrates that all statistical techniques are 
individually as well as collectively effective in sex determination. Special attention was paid to develop standards for ends of femur, so that sex can be determined even if fragmentary remains are available. The classification accuracy increases with increase in number of parameters. In addition, the demarcating values and limiting values found out in this study can help set up baseline parameters for sex determination in the North Indian population.

\section{REFERENCES}

1. Standring $S$, Borley NR, Coliins P, et al. Gray's anatomy the anatomical basis of clinical practice. In: Girdle P, Region G, Thigh. $40^{\text {th }}$ ed. Spain, Elsevier Churchill Livingstone. Ch 80. 2008:1360-5.

2. Hema N, Bhagya B, Sucharitha S, et al. Metric assessment of femur using discriminant function analysis in south Indian population. Int J Anat Res 2013;1(2):29-32.

3. Rashmi S, Vineeta S, Rajesh KR, et al. A study of sexual dimorphism in the femur among north Indians. J Forensic Sci 2011;57(1):19-23.

4. Krogman WM, Thomas CC, Springfield. The human skeleton in forensic medicine. AJO-DO 1963;49(6):474.

5. Black TK. A new method for assessing the sex of fragmentary skeletal remains: femoral shaft circumference. Am J Phys Anthrop 1978;48:227-32.

6. Igbigbi PS, Msamati BC. Sex determination from femoral head diameters in black malawains. East Afr Med J 2000;77(3):147-51.

7. Purkait R, Chandra H. Sexual dimorphism in femora: an Indian study. Forensic Sci Commun 2002;4(3):1-6.

8. Pavel T, Antoaneta F, Dobrinka R, et al. A study of sexual dimorphism in the femur among contemporary Bulgarian population. Euras J Anthropol 2014;5(1):46-53.
9. Krogman WM, Iscan MY. Human skeleton in forensic medicine. $2^{\text {nd }}$ ed. Thomas CC, Springfield 1986.

10. Pandya AM, Singel TC, Akbari VJ, et al. Sexual dimorphism of maximum femoral length. Nat J Med Res 2011;1(2): 67-70.

11. Kate BR. A study of the regional variation of the Indian femur-the diameter of the head-its medicolegal and surgical application. J Anat Soc India 1964;13(1):80-4.

12. Laeeque MD, Vivek N, Diwan CV. Determination of sex of femur by combination of parameters. Int J Basic Med Sci 2013;3(6):173-7.

13. Bhosale RS, Zambare BR. Sex determination from femur using length of femur in Maharashtra. IOSR Journal of Dental and Medical Sciences 2013;3(4):1-3.

14. DiBennardo $\mathrm{R}$, Taylor JV. Classification and misclassification in sexing the black femur by discriminant function analysis. Am J Phys Anthrop 1982;58(2):145-51.

15. Gargi S, Usha D, Sudha C. Determination of sex from femur: discriminant analysis. J Anat Soc India 2010; $59(2): 216-21$.

16. King CA, Iscan MY, Loth SR. Metric and comparative analysis of sexual dimorphism in the Thai femur. J For Sci 1998;43(5):954-8.

17. Ismail 0 , Katayama K. Sex determination using the femur in an ancient Japanese population. Coll Antropol 2008; 32(1):67-72.

18. Wu L. Sex determination of Chinese femur by discriminant function. J For Sci 1989;34(5):1222-7.

19. Urvik CK, Tulsibhai CS, Pratik NT, et al. Sex determination from vertical diameter of femoral head in Gujarati population. Int J Adv Res 2014;2(6):859-63. 